\title{
The Corrosion Inhibition of Mild Steel in Acid Solutions media by Adsorption of leaves of Morus nigra L. from Libya
}

\author{
Ali Ramadan Alkais ${ }^{1}$, Salem Mohamed Edrah ${ }^{2}$ \\ ${ }^{1}$ El- Mergeb University, Chemical Engineering Department, Engineering College \\ ${ }^{2}$ Chemistry Department, Science College, El- Mergeb University
}

\begin{abstract}
The inhibition of mild steel corrosion in hydrochloric acid solutions were studied with application of Libyan plant Leave (Morus nigra L.) on mild steel in 1M HCl (37 \% Hydrochloric acid) using weight loss method and gravimetric measurements. Experiments were performed by varying immersion period concentration of the inhibitor. Corrosion inhibition efficiency of (Morus nigra $L$ ) leaves extracts was evaluated using weight loss measurements for effect of various solution concentrations sustained at optimum concentration $1 \mathrm{~g} / \mathrm{l}$ was $85.6 \%$ in $1 \mathrm{M} \mathrm{HCl}$ acid with $2 \%$ plant crude extract and it was increased with the increase in concentration of plant leaves crude extract at temperature $25^{\circ} \mathrm{C}$. Maximum inhibition efficiency was found $94.9 \%$ in $1 \mathrm{M} \mathrm{HCl}$ acid with $10 \%$ plant crude extract. The corrosion rate was found to decrease with the increases in concentration of extract up to $0.3 \%$ to $1.2 \%$. The results obtained indicate that the crude extracts functioned as decent inhibitors in $1 \mathrm{M} \mathrm{1.0} \mathrm{HCl.} \mathrm{The} \mathrm{adsorption} \mathrm{of} \mathrm{constituents}$ in the plant crude extract on the surface of the metal is proposed for the inhibition behavior. Also the crude extract was analyzed for electrical conductivity (Ec), total dissolved salts (TDS) and pH values.
\end{abstract}

Keywords: Mild steel, Crude Extract, Hydrochloric acid solutions, Adsorption, Corrosion

\section{Introduction}

Numerous protective measures taken for controller and prevent the corrosion one of them being the use of inhibitors. [1]- [2]-[3] A corrosion inhibitor is a substance which, when added to a corrosive environment significantly decreases the rate of corrosion attack caused by the environment. Corrosion inhibitors are commonly added in small amounts to pickling acids, acid stimulation fluids, cooling waters, oil and gas production streams, either continuously or intermittently to control corrosion. Mild steel certainly is cheapest and most commonly used in construction material, were used extensively for centuries in many areas, intended for water pipes, boats, docks, tanks vessels, etc. Because of its low nobility and structural defects, mild steel, in interaction with other metals, corrodes practically in all environments [4]. Mild steel can be protected by using organic or inorganic species to the solution in order to inhibit the corrosion reaction in acid media, the most common amongst these are the inhibitors based on inorganic nitrites, nitrogen-based materials and their derivatives such as Sulphur containing compounds, aldehydes, thioaldehydes, acetylenic compounds, and various alkaloids such as papaverine, strychnine, quine, and nicotine have been employed as inhibitors. In neutral media, benzoate, nitrite, chromate and phosphate act as good inhibitors. [5]- [6] The adsorption bond strength is dependent on the composition of the metal and the corroding, the inhibitor structure and the concentration as well as the temperature. [7]-[8] The aim of this study was to investigate inhibition effect (losses weight, inhibition efficiency and corrosion rate) of Morus nigra L. leaves extract as a cheap, raw and non-toxic corrosion inhibitor on steel corrosion in leaves hydrochloric acid. The toxic effects of synthetic corrosion inhibitors have led to the search for naturally occurring substances which are not only readily available but are also environmentally friendly and along with that fact of naturally occurring plant products are ecofriendly, less toxic, less expensive and non-polluting consequently can widely be used without side effect. Hence, this study investigates the inhibition efficacy of acid extract of Morus nigra L. leaves on mild steel in $1 \mathrm{M} \mathrm{HCl}$ using weight loss method.

\section{Materials and Methods}

\subsection{Preparation of Metal Specimen}

The mild steel specimens were mechanically cut in to dimension of $1 \mathrm{~cm} \mathrm{x} 4 \mathrm{~cm} \times 1 \mathrm{~mm}$ thickness (with a surface area of $4 \mathrm{~cm}^{2}$, one face). Prior to all, the mild steel coupons were mechanically polished with series of emery paper from 400 to 1200 grades. The specimen are washed thoroughly with distilled water, degreased with absolute ethanol, dipped into acetone and dried in air. The dried specimens stored in desiccators before used.

\subsection{Preparation of Inhibitor (crude extracts)}

The fresh leaves of Morus nigra L. were abundantly collected at Alkhums Region, Libya in Mars/ April months of 2015. The plant were identified by Plant taxonomist of the Department of Biology of El-Mergheb University, AlKhums, Libya The leaves were washed thoroughly with tap water then by distilled water to remove undesirable material. The sample were shield dried, grinded in to fine powder and weighed ground leaves were stored in desiccators prior to usage. $20 \mathrm{~g}$ of ground samples was extracted by Soxhlet with distilled water (at a $40 \%(\mathrm{w} / \mathrm{v})$ concentration $20 \mathrm{~g}$ leaves powder in $400 \mathrm{ml}$ distilled water) for 6 hours after that 


\section{International Journal of Science and Research (IJSR) \\ ISSN (Online): 2319-7064}

Index Copernicus Value (2013): 6.14 | Impact Factor (2015): 6.391

filtered off. The aqueous crude extracts were stored in refrigerator at $4^{\circ} \mathrm{C}$ until further use.

\subsection{Preparation of Test Solutions}

The solution of $\mathrm{M} 1.0 \mathrm{HCl}$ (37 \% $\mathrm{HCl}$ Hydrochloric acid) was prepared by diluting with distilled water. The inhibitors were accurately weighed and dissolve in prepared $\mathrm{M} 1.0 \mathrm{HCl}$ acid solutions to obtain different inhibitors concentrations (2\%, 4\%, 6\%, 8\% and 10\%). The test solutions were prepared in different containers to carry out the corrosion experiment.

\subsection{Temperature}

Altogether experiments were carried out at the room temperature $25 \pm 2{ }^{\circ} \mathrm{C}$

\section{5pH Value}

pH was measured using a model HI 8014 USA Hanna Instrument, $\mathrm{pH}$-meter. It was observed from the $\mathrm{pH}$ value that aqueous extract sample was 5.13.

\subsection{Electrical conductivity (or salinity) and total dissolved solids}

Prepared 20\% (w/v) solution of crude extract suspended in deionizer water. The electrical conductivity and total dissolved solids of each sample were analyzed three times, and the mean values were expressed in $\mu \mathrm{S} / \mathrm{cm}$ and ppm, respectively, the deionizer water was determined to be less than $10 \mu \mathrm{S} / \mathrm{cm}$. [9] The electric conductivity/ TDS were determined with a model Jenway 4520 Conductivity Meter. It was observed from the $\mathrm{pH}$ value ( Hanna Instrument, HI 8014, pH Meter) that aqueous extract sample was for Ec $72.3 \mu \mathrm{S} / \mathrm{cm}^{3}$ and for TDS $43.3 \mathrm{mg} / \mathrm{lit}$.

\subsection{Gravimetric measurements}

Weight loss measurements were conducted under total immersion using $250 \mathrm{ml}$ capacity plastic containing prepared solution at $25{ }^{\circ} \mathrm{C}$. The mild steel coupons were weighed and dropped in the corroding with the aid of acid resistance plastic clip. The coupons were retrieved for appropriate time (24, 48, 72 and 96 hours). After each exposure time, the mild steel coupons were removed, from the vessel and brushed with a stiff brush under running water to remove all loose deposit then rinsed with distilled water and dried by acetone. The mild steel was re-weighed to determine the weight loss, in gram by the difference of mild steel weight before and after immersion. The corrosion rates $\left(\mathrm{g} / \mathrm{cm}^{2} \mathrm{~h}\right)$ in the absence and presence of the considered inhibitors were determined. Weight loss was calculated by finding the difference between weight of each coupon before and after immersion (1);

$$
\mathrm{W}=W b-W a(1)
$$

$W b$ is the weight before immersion; $W a$ is the weight after immersion. While the corrosion rate $\left(\mathrm{g} / \mathrm{cm}^{2} \mathrm{~h}\right)$ in absence and presence of inhibitors was calculated using following equation (2):

$$
C R=\Delta w A t
$$

Where $\Delta w$ is the weight loss (g) after exposure time $\mathrm{t}(\mathrm{h}), \mathrm{A}$ is the area of the specimen $\left(\mathrm{cm}^{2}\right)$ and $\mathrm{t}$ is time of exposure in hours, and $\mathrm{CR}$ is the corrosion rate at each exposure time.

\subsection{Evaluation of Corrosion Parameters}

The parameters of corrosion include corrosion rates (CR) and inhibition efficiency (IE \%), calculated from weight loss measurements for mild steel in acid media with absent and presence of various concentrations of leaves extract ( $2 \%$, $4 \%, 6 \%, 8 \%$ and $10 \%)$ for a period of time $(24,48,72$ and 92 hours), at temperatures $25{ }^{0} \mathrm{C}$. (3)

Inhibitor Efficiency (\%) $=100 \cdot\left(\right.$ Un $_{\text {inhibited }}$ In $\left._{\text {hibited }}\right) /$

$$
\text { Un } \text { inhibited. }_{\text {. }}
$$

Where:

Uninhibited $=$ corrosion rate of the uninhibited system. Inhibited $=$ corrosion rate of the inhibited system.

\section{Result and Discussion}

3.1 Physico chemical properties of raw water samples Table 1: Physico-chemical parameters of (plant extract)

\begin{tabular}{|c|c|c|c|c|}
\hline parameters & Time $^{\circ} \mathrm{C}$ & $\mathrm{pH}$ & $\mathrm{EC} \mu \mathrm{S} / \mathrm{cm}^{3}$ & TDS mg \\
\hline plant extract & 25 & 5.13 & 72.3 & 43.3 \\
\hline
\end{tabular}

\subsection{The pH value, TDS and Electrical Conductivity EC}

As showed in Table 1 it was observed from the $\mathrm{pH}$ value that aqueous extract sample was 5.13 and the TDS values for the crude extract was $43.3 \mathrm{mg} / \mathrm{l}$, where electrical conductivity EC which is a factor in the determination one of the substantial physical characteristics of the crude plant extract it was $72.3 \mu \mathrm{S} / \mathrm{cm}^{3}$ and this parameter depends on the plant constituents such as organic acids some complex sugars and polyols content, and varies with botanical origin. The electrical conductivity of the extract is closely associated to the concentration of mineral salts and organic acids; it is a parameter that shows countless variability consistent with the floral origin. [10]

Table 2: Corrosion parameters for mild steel in $1 \mathrm{M} \mathrm{HCl}$ in absence and presence of optimum concentration of the inhibitor studied at 24 hours

\begin{tabular}{|c|c|c|c|}
\hline $\begin{array}{c}\text { Immersion } \\
\text { Time (h) }\end{array}$ & \multicolumn{3}{|c|}{24} \\
\hline Concentration & $\begin{array}{c}\text { Weight loss } \\
\text { (gr) }\end{array}$ & $\begin{array}{c}\text { Corrosion rate } \\
\text { (gr/cm }{ }^{2} \text { day) }\end{array}$ & $\begin{array}{c}\text { Inhibition } \\
\text { Efficiency \% }\end{array}$ \\
\hline HCL blank & 0.0714 & 0.008925 & 0.00 \\
\hline $2 \%$ & 0.0468 & 0.005850 & 34.4 \\
\hline $4 \%$ & 0.0154 & 0.001925 & 78.4 \\
\hline $6 \%$ & 0.0265 & 0.003312 & 62.8 \\
\hline $8 \%$ & 0.0184 & 0.002300 & 74.2 \\
\hline $10 \%$ & 0.0114 & 0.001425 & 84.0 \\
\hline
\end{tabular}




\section{International Journal of Science and Research (IJSR) \\ ISSN (Online): 2319-7064}

Index Copernicus Value (2013): 6.14 | Impact Factor (2015): 6.391

Table 3: Corrosion parameters for mild steel in $1 \mathrm{M} \mathrm{HCl}$ in absence and presence of optimum concentration of the inhibitor studied at 48 hours:

\begin{tabular}{|c|c|c|c|}
\hline $\begin{array}{c}\text { Immersion } \\
\text { Time (h) }\end{array}$ & \multicolumn{3}{|c|}{48} \\
\hline Concentration & $\begin{array}{c}\text { Weight loss } \\
\text { (gr) }\end{array}$ & $\begin{array}{c}\text { Corrosion rate } \\
\text { (gr/cm }{ }^{2} \text { day) }\end{array}$ & $\begin{array}{c}\text { Inhibition } \\
\text { Efficiency \% }\end{array}$ \\
\hline HCL blank & 0.2062 & 0.025775 & 0.00 \\
\hline $2 \%$ & 0.0285 & 0.003562 & 86.1 \\
\hline $4 \%$ & 0.0105 & 0.001312 & 94.9 \\
\hline $6 \%$ & 0.0188 & 0.002350 & 90.8 \\
\hline $8 \%$ & 0.0218 & 0.002725 & 89.4 \\
\hline $10 \%$ & 0.0139 & 0.001737 & 93.2 \\
\hline
\end{tabular}

Table 4 Corrosion parameters for mild steel in $1 \mathrm{M} \mathrm{HCl}$ in absence and presence of optimum concentration of the inhibitor studied at 72 hours

\begin{tabular}{|c|c|c|c|}
\hline $\begin{array}{c}\text { Immersion } \\
\text { Time (h) }\end{array}$ & \multicolumn{3}{|c|}{$72 \mathrm{~h}$} \\
\hline Concentration & $\begin{array}{c}\text { Weight loss } \\
\text { (gr) }\end{array}$ & $\begin{array}{c}\text { Corrosion rate } \\
\left(\mathrm{gr} / \mathrm{cm}^{2} \text { day) }\right.\end{array}$ & $\begin{array}{c}\text { Inhibition } \\
\text { Efficiency \% }\end{array}$ \\
\hline Hcl blank & 0.2058 & 0.025725 & 0.00 \\
\hline $2 \%$ & 0.0570 & 0.007125 & 72.3 \\
\hline $4 \%$ & 0.0470 & 0.005875 & 77.1 \\
\hline $6 \%$ & 0.0593 & 0.007412 & 71.1 \\
\hline $8 \%$ & 0.0421 & 0.005262 & 79.5 \\
\hline $10 \%$ & 0.0268 & 0.003350 & 86.9 \\
\hline
\end{tabular}

Table 5 Corrosion parameters for mild steel in $1 \mathrm{M} \mathrm{HCl}$ in absence and presence of optimum concentration of the inhibitor studied at 96 hours:

\begin{tabular}{|c|c|c|c|}
\hline $\begin{array}{c}\text { Immersion } \\
\text { Time (h) }\end{array}$ & \multicolumn{3}{|c|}{$96 \mathrm{~h}$} \\
\hline Concentration & $\begin{array}{c}\text { Weight loss } \\
\text { (gr) }\end{array}$ & $\begin{array}{c}\text { Corrosion rate } \\
\left(\mathrm{gr} / \mathrm{cm}^{2} * \text { day) }\right.\end{array}$ & $\begin{array}{c}\text { Inhibition } \\
\text { Efficiency \% }\end{array}$ \\
\hline Hcl blank & 0.4613 & 0.057662 & 0.00 \\
\hline $2 \%$ & 0.0705 & 0.008812 & 84.7 \\
\hline $4 \%$ & 0.0283 & 0.003537 & 93.8 \\
\hline $6 \%$ & 0.0382 & 0.004775 & 91.7 \\
\hline $8 \%$ & 0.0384 & 0.004800 & 91.6 \\
\hline $10 \%$ & 0.0300 & 0.003750 & 93.4 \\
\hline
\end{tabular}

The corrosion rates and inhibition efficiency values, calculated using weight loss data, for various concentrations of Morus nigra L. leaves extract in the presence of $1 \mathrm{M} \mathrm{HCl}$ of the corrosion solution are presented in Tables.2, 3, 4 and 5 , Wherever the weight loss was found decreasing with increase in concentration of inhibitor, the corrosion product formed from the reaction of mild steel with corrosive media to form this stable compound (corrosion product). Along with Properties and consequently losing weight of mild steel leads to continue of corrosion product, the inhibition efficiency and the values of corrosion rate presented in tables 2, 3, 4 and 5 at room temperature revealed. These values of corrosion rate and inhibition efficiency at room temperature, showed the studied plant extracts act as decent corrosion inhibitors and the obtained corrosion rate result decreased with addition of sample leaves extract. The corrosion rate value obtained was used to determine the inhibition efficiency of the studied leaves extract in corrosion manner. Significant, cleared that the inhibition efficiency increases with increase in concentration of inhibitor. The decrease in inhibition efficiency was likewise a result of desorption of some inhibitor substituent. Outer layer of dimeric inhibitor film and at the same time the underlying layer effectively protect the metal surface from acid attack and the exposure of mild steel to acidic media for longer period of time results in high corrosion rate and fall of inhibition efficiency. [11]

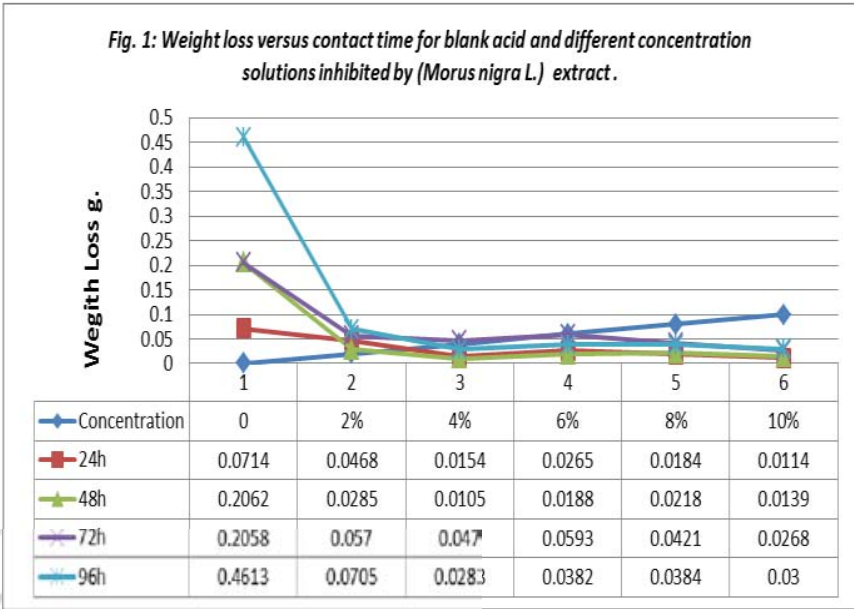

Figure 1: Weight loss versus contact time for blank acid and solutions inhibited by plant Leave (Morus nigra L.) extract at $25^{\circ} \mathrm{C}$.

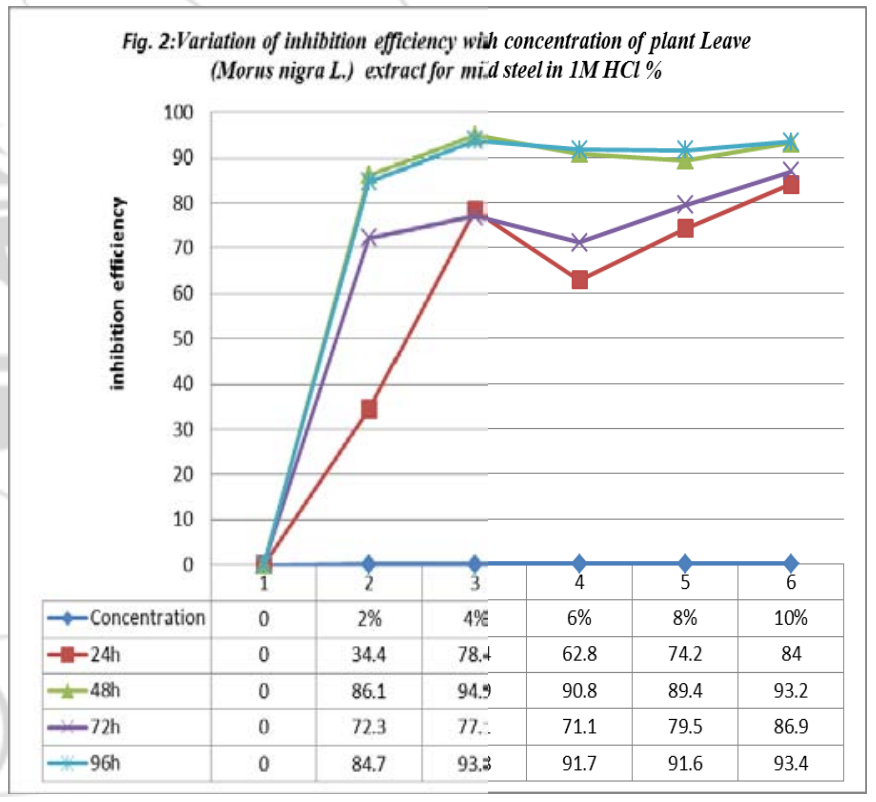

Figure 2: Variation of inhibition efficiency with concentration of plant Leave (Morus nigra L.) extract for mild steel in $1 \mathrm{M} \mathrm{HCl} \%$ :

A mechanism of chemical adsorption on the extract components on the surface of the metal is proposed for the inhibition behavior. In consort with the inhibition efficiency increases with increasing concentration of inhibitor in each solution in addition to it decreases with increasing strength of $\mathrm{HCl}$ solution, Corresponding compare values for the variation in reaction number with concentration of inhibitor were represented in figures 1 and 2 for different concentration of $\mathrm{HCl}$ solution, Where figures 3,4 and 5 represented visual images of the mild-steel specimens before and after immersion in different concentrations of extracts and solution of $\mathrm{M} 1.0 \mathrm{HCl}$ intended for period time. This study showing that corrosion inhibition may be due to the natural physical adsorption of the plant constituents on the

\section{Volume 5 Issue 4, April 2016}




\section{International Journal of Science and Research (IJSR) \\ ISSN (Online): 2319-7064}

Index Copernicus Value (2013): 6.14 | Impact Factor (2015): 6.391

surface of mild steel. The effect of concentration on corrosion rate exhibited the variation of corrosion rate of mild steel in $1 \mathrm{M} \mathrm{HCl}$ in the presence of various concentrations of acid extract of Morus nigra L. was studied at room temperature. The results illustrations that the corrosion rate of mild steel in $1 \mathrm{M} \mathrm{HCl}$ decreases with increase in the concentration of the extracts at room temperature. This suggests that as the concentration of the extract increases, there is an increase in the number of adsorption of the extract constituents on the surface of the mild steel which makes a barrier for mass transfer and prevents further corrosion. [12] The role of inhibitors is to form a barrier of one or several molecular layers against acid attack and this depends on phytochemical compounds which vary widely on the part of the plant and its geographical location. [13] The inhibitive characteristics of such compounds derive from the adsorption ability of their molecules, with the polar group acting as the reaction center for the adsorption process. [14] The resulting adsorbed film acts as a barrier that separates the metal from the corroding, and efficiency of inhibition depends on the mechanical, structural, and chemical characteristics of the adsorption layers formed under particular conditions. [15] It was previously reported that bitter leaves extract in the literature that they contained many phytochemical compounds like tannins, saponins, alkaloids, and flavonoids. [16]

\section{Conclusion}

The cause of concentration on corrosion rate exhibited the variation of corrosion rate of mild steel in $1 \mathrm{M} \mathrm{HCl}$ in the presence of various concentrations of acid extract of Morus nigra $L$ result in revelation suitable results by means of such an inhibitor. The aqueous extract of Morus nigra L. plant acts as good inhibitor for the corrosion of mild steel in $1 \mathrm{M}$ $\mathrm{HCl}$ solution. The inhibitor exhibit agreeable inhibition efficiency on mild steel corrosion in $\mathrm{HCl}$ solution than the leave samples the inhibition efficiency increase with increase in concentration of inhibitors as $93.4 \%$ in $10 \%$ of plant leaves concentration obtained at $25 \pm 2{ }^{\circ} \mathrm{C}$ for 96 hours and as $34.4 \%$ in $2 \%$ of plant leaves concentration obtained at the same temperature for 24 hours.

\section{Acknowledgement}

The authors generously acknowledge the support by Department of Chemistry, Science College Alkhums ElMergeb University, Libya. And Department of Chemical Engineering, Engineering College, Alkhums, El-Mergeb University, Libya for providing necessary chemical and lab facilities to carry out chemical studies.

\section{References}

[1] G.G. Eldredge, J.C. Warner: 'The Corrosion Handbook', (ed. H.H. Uhlig), 1948, 905, New York, Wiley.

[2] C.C. Nathan: 'Corrosion Inhibitors' 1973, Houston, Texas, National Association of Corrosion ngineers (NACE).
[3] M.W. Ranney: Inhibitors-Manufacture and Technology, 1976, New Jersey, Noyes Data Corp.

[4] R.R. Pierre, in: R.W. Revie (Ed.), Corrosion Inspection and Monitoring, Wiley Series in Corrosion, John Wiley \& Sons, Inc., Hoboken, New Jersey, 2007.

[5] Singh, A. and Quraishi, M.A. Pipali (Piper longum) and Brahmi (Bacopa monneiri) extracts as green corrosion inhibitor for aluminium in $\mathrm{NaOH}$ solution. Journal of Chemical and Pharmaceutical Research, 2012; 4(1): 322-325.

[6] Okafor, P.C., Ebiekpe, V. E., Azike, C.F., Egbung, G.E., Brisibe, E. A., Ebenso, E. E. Inhibitory action of Artemisia annua extracts and artemisinin on the corrosion of mild steel in $\mathrm{H} 2 \mathrm{SO} 4$ solution. International Journal of Corrosion, 2012; rticle ID 768729.

[7] Quraishi, M. A., Yadav, D. K., Ahamad, I. Green approach to corrosion inhibition by black pepper extract in hydrochloric acid solution. Open Corrosion Journal, 2009; 2: 56-60.

[8] Saratha, R. and Vasudha, V.G. Inhibition of mild steel corrosion in $1 \mathrm{~N}$ H2SO4 medium by acid extract of Nyctanthes arbortristis leaves. EJournal of Chemistry, 2009; 6(4): 1003-1008.

[9] Shehab Ahmed Lafi, Huda R. Sabar Al-Dulaimy, Muntaha M. Al-Aloosi, Anb, Mar. 2012 Med J Vol.10 No.1; 13-17.)

[10]KebedeNigussie, P.A. Subramanian and GebrekidanMebrahtu, Bull. Chem. Soc. Ethiop. 2012, 26(1), 127-133.

[11] Solomon, M. M., Umoren, S. A., Udosoro, I. I., Udoh, A. P., Inhibitive and adsorption behavior of carboxymethyl cellulose on mild steel corrosion in sulphuric acid solution. Corrosion science, Volume 52, page 1317-1325, 2010.

[12] Wabanne, J.T. and Okafor, V. Inhibition of the corrosion of mild steel in acidic medium by Vernonia amygdalina: Adsorption and Thermodynamics study. Journal of Emerging Trends in Engineering and Applied Sciences, 2001; 2 (4): 619-625.

[13] Oguzie, E. E., (2007). Corrosion inhibition of aluminium in acidic and alkaline media by Sansevieria trifasciata extract. Corrosion Science. Volume 49, number 3, page 1527

[14] Amitha Rani, B. E., Bharathi Bai, J. B., (2012). Green inhibitors for protection of metals and alloys. International Journal of corrosion, volume 2012, page 15.

[15] Amitha Rani, B. E., Bharathi Bai, J. B., (2012). Green inhibitors for protection of metals and alloys. International Journal of corrosion, volume 2012, page 15.

[16]Debi,G.E., H. Esah, I. Mohammed, A.S. Abdulrahman and M. Aminu, 2013. "Effect of Vernonia Amygdalina Extract on Corrosion Inhibition of Mild Steel in Simulated seawater. Australian Journal of basic and Applied Sciences. Volume 7, number 14, pp: 257-263. 


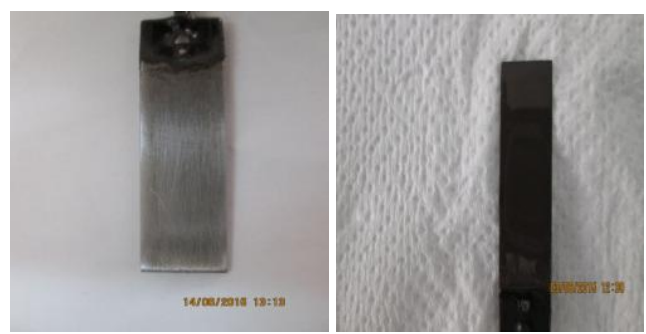

(a) Before (b) After

Figure 3 Visual images of the mild-steel specimens before and after immersion in in the solution of M $1.0 \mathrm{HCl}$ for $24 \mathrm{~h}$
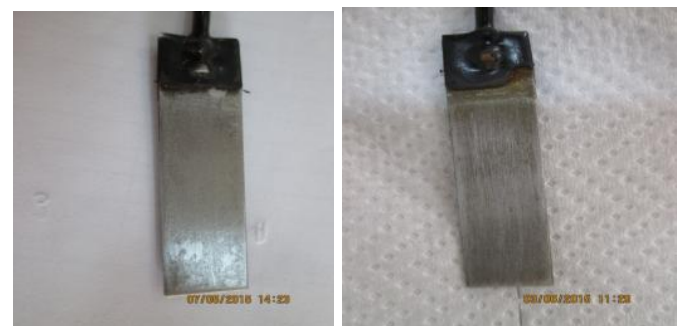

(a) Before (b) After

Figure 4: Visual images of the mild-steel specimens before and after immersion in the solution of $\mathrm{M} 1.0 \mathrm{HCl}$ and $2 \%$ inhibitor for $24 \mathrm{~h}$
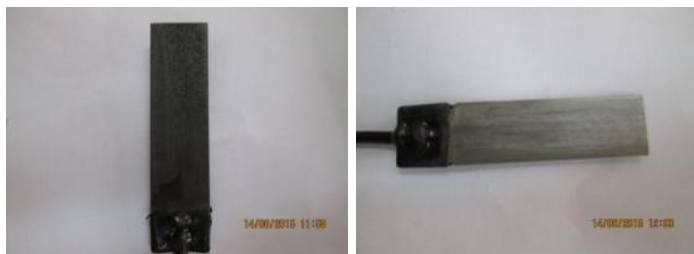

(a)Without inhibitor for 96h (b) with10\% inhibitor for $96 \mathrm{~h}$

Figure 5: Visual images of the mild-steel specimens immersing in the solution of $\mathrm{M} 1.0 \mathrm{HCl}$ with and without $10 \%$ inhibitor for $96 \mathrm{~h}$

\section{Author Profile}

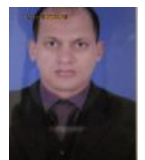

Dr. Ali Ramadan Elkais, Education: 1989-1994: BSc. Chemical Engineering from Tripoli University, Tripoli, Libya. 2003-2004, MSc. Full time Master of Science, Corrosion Control from Manchester University, U.K. 2008-2013: Ph.D. Chemical Engineering from Belgrade University. Belgrade. Serbia. Experience: 2013 - Present: Post-Doctoral Research Scientist, Chemical Engineering Department, El-Mergeb University, Alkhums Libya. 1997 - 2007: Eni Oil Company-Libyan Branch, Offshore Bouri field on Central Platform (DP4).

Dr. Salem Mohamed Edrah, Assistance Professor's, PhD, Eng.: 2001, 2008: received the Masters and Ph. $\mathrm{D}$ degrees in Chemistry from Pardubice University. 2013-2014: worked as PDF, RA, in Universities in Pardubice (Czech Republic). 1998 onwards: worked / working as Faculty member and Principal in Academic Institutions situated in El-Mergeb University, Al-khums (Libya) Teaching Specializations: Organic Chemistry, Biochemistry. Natural Products, Research Specializations: Synthetic Organic Chemistry, Phytochemistry etc. 